\title{
Diseminasi Informasi Terkait Pariwisata Berwawasan Lingkungan dan Budaya Guna Meningkatkan Daya Tarik Wisatawan (Studi pada Dinas Pariwisata Provinsi Nusa Tenggara Barat)
}

\author{
Yugih Setyanto, Septia Winduwati \\ Fakultas Ilmu Komunikasi Universitas Tarumanagara \\ yugihs@fikom.untar.ac.id, septiaw@fikom.untar.ac.id
}

\begin{abstract}
Tourism is a huge potential owned by the regions in Indonesia. Many areas in Indonesia that actually has an interesting potential to be developed into tourism object. In order for the potential to have a selling power that attracts potential tourists to come should be disseminated information about the object. The process of information dissemination is adjusted to various things such as the intended audience and what potentials need to be known by the audience. Therefore, each local government has the authority in developing and promoting tourism potential that exists. The local government seeks the promotion of regional tourism potentials through dissemination of information to the public. Roles and functions are carried out so that the potential of tourism areas that are environmentally and culturally relevant tourism can be maximally known by the public and increase the attractiveness of tourists, especially domestic and foreign tourists.
\end{abstract}

Keywords: communication, information dissemination, tourism communication

\begin{abstract}
Abstrak
Penelitian ini merupakan studi terkait upaya diseminasi informasi di bidang komunikasi pariwisata. Pariwisata merupakan potensi yang sangat besar dimiliki oleh daerah-daerah di Indonesia. Banyak daerah di Indonesia yang sebenarnya memiliki potensi yang menarik untuk dikembangkan menjadi objek pariwisata. Agar potensi tersebut memiliki daya jual yang menarik minat calon wisatawan untuk datang harus dilakukan penyebaran informasi mengenai objek tersebut. Proses diseminasi informasi disesuaikan berbagai hal misalnya khalayak yang dituju dan potensi apa yang perlu diketahui oleh khalayak. Oleh sebab itu, masing-masing pemerintah daerah memiliki otoritas dalam mengembangkan serta mempromosikan potensi wisata yang ada. Pemda mengupayakan promosi potensi wisata daerah melalui diseminasi informasi ke publik. Peran dan fungsi tersebut dilakukan sehingga potensi wisata daerah yakni pariwisata yang berwawasan lingkungan dan budaya bisa secara maksimal dikenal oleh masyarakat dan meningkatkan daya tarik wisatawan, khususnya turis dalam dan luar negeri.
\end{abstract}

Kata kunci: diseminasi informasi, komunikasi, komunikasi pariwisata

\section{Pendahuluan}

Indonesia merupakan negara yang kaya dengan kekayaan alam dan hasil kesenian penduduknya. Indonesia yang terkenal akan keindahan alamnya juga merupakan salah satu destinasi wisata baik oleh wisatawan dalam negeri, maupun 
luar negeri. Di Asia Tenggara, Indonesia adalah negara dengan luas wilayah terbesar, terdiri atas ribuan pulau besar dan kecil, Indonesia dengan garis pantai yang sangat panjang juga memiliki laut dan hamparan pantai yang indah sebagai tempat wisatawan melakukan aktivitas wisata bahari seperti menyelam, berselancar atau sekadar menikmati panorama pantai. Kondisi iklimnya yang mendapat sinar matahari sepanjang tahun membuat aktivitas kepariwisataan tidak dipengaruhi oleh pergantian musim. Selain itu, Indonesia terdiri atas lebih dari 500 suku (etnis), dengan bahasa dan budaya yang beraneka ragam. Keragaman suku dan budaya tersebut menjadikan Indonesia sebagai destinasi wisata dunia yang sangat kaya akan atraksi wisata budaya dan kuliner yang unik dan beragam.

Hal tersebut yang menjadikan pemerintah melalui Kementerian Pariwisata mengalokasikan dana khusus dari tahun ke tahun. Tahun ini, seperti yang ditulis di Suara Merdeka.com, pemerintah meningkatkan alokasi dana di bidang pariwisata sebanyak tiga kali lipat dibandingkan tahun kemarin. Melalui sektor pariwisata, perekonomian masyarakat yang tinggal di seputar daerah berpotensi wisata tersebut tentu akan meningkat juga. Namun demikian, pengelolaan daerah pariwisata pun harus tepat, bertanggung jawab dan berkesinambungan. Berdasarkan Peraturan Menteri Pariwisata dan Ekonomi Kreatif Nomor: PM.07/HK.001/MPEK/2012 Tanggal 13 Februari 2012 Tentang Organisasi dan Tata Kerja Kementerian Pariwisata dan Ekonomi Kreatif, pada pasal 8 dijelaskan bahwa dalam melaksanan tugas fungsi utama dari Kementerian Pariwisata dan Ekonomi Kreatif adalah sebagai berikut (sumber: www.parekraf.go.id):

a) Perumusan, penetapan, dan pelaksanaan kebijakan di bidang pariwisata dan ekonomi kreatif;

b) Pengelolaan barang milik/kekayaan negara yang menjadi tanggung jawab Kementerian Pariwisata dan Ekonomi Kreatif;

c) Pengawasan atas pelaksanaan tugas di lingkungan Kementerian Pariwisata dan Ekonomi Kreatif;

d) Pelaksanaan bimbingan teknis dan supervisi atas pelaksanaan urusan Kementerian Pariwisata dan Ekonomi Kreatif di daerah; dan

e) Pelaksanaan kegiatan teknis yang berskala nasional.

Berdasarkan fungsi tersebut, maka dapat disimpulkan bahwa seluruh perencanaan dan pelaksanaan kegiatan dalam mempromosikan pariwisata menjadi tanggung jawab Kementerian Pariwisata dan Ekonomi Kreatif, dan untuk kegiatan di daerah-daerah dibantu oleh Dinas Pariwisata masing-masing daerah. Dengan demikian, masing-masing pemerintah daerah memiliki otoritas untuk mengembangkan pariwisatanya.

Dinas Pariwisata dan Budaya Provinsi NTB pun telah membuat perencanaan branding wisata untuk tahun 2016 dengan tajuk "Pesona Lombok Sumbawa". Branding Wisata yang disusun dan direncanakan tersebut menyesuaikan dengan sumber daya yang paling potensial dimiliki oleh daerah tersebut. Mengingat Nusa Tenggara Barat memiliki potensi besar di sumber daya alam dan budayanya, maka pengelolaan pariwisata yang berwawasan lingkungan atau pariwisata berbasis alam (nature) dan budaya sangat tepat jika dijadikan andalan. 
Yugih Setyanto, Septia Winduwati : Diseminasi Informasi Terkait Pariwisata Berwawasan Lingkungan dan Budaya Guna Meningkatkan Daya Tarik Wisatawan (Studi pada Dinas Pariwisata Provinsi Nusa Tenggara Barat)

Provinsi Nusa Tenggara khususnya Pulau Lombok bersama dengan Bali telah ditetapkan sebagai pintu gerbang pariwisata Nasional dalam MP3EI Koridor V (Masterplan Percepatan dan Perluasan Pembangunan Ekonomi Indonesia). Pariwisata NTB membutuhkan strategi untuk memperkenalkan destinasi wisata yang ada di daerahnya agar lebih dikenal. Untuk itu perlu pendekatan Public Relations dalam mengimplementasikannya. Alasan penerapan public relations adalah karena salah satu fungsinya dalam menyebarluaskan informasi dengan fokus komunikasi pariwisata kepada masyarakat luas melalui program diseminasi informasi, khususnya para wisatawan potensial.

Salah satu upaya yang bisa dilakukan adalah dengan melakukan diseminasi informasi, khususnya yang terkait dengan informasi dan komunikasi pariwisata berbasis lingkungan dan budaya (eco-tourism) daerah provinsi Nusa Tenggara Barat kepada masyarakat luas. Menurut Tulung (2014) diseminasi informasi adalah penyebarluasan informasi dan sebuah penyampaian pesan komunikasi yang dapat terjadi jika pengguna mengalami internalisasi yaitu pengguna menerima pesan atau memerlukan informasi yang sesuai dengan harapan dan kebutuhannya sehingga memberikan manfaat baginya. Ia juga menjelaskan bahwa manajemen informasi tersebut menjadi bagian dalam pelaksanaan kehumasan pemerintah dan harus dikelola oleh aparat birokrasi yang telah terlatih dan memiliki kapasitas keilmuan serta berpengalaman dalam praktik PR yang memadai. Dalam pengertian yang lain mengenai diseminasi disampaikan Welch-Ross dan Fasig (2007) dissemination of behavioral science refers to the spreading innovations from science to promote widespread awerness, understanding and use. Dari dua penjelasan mengenai diseminasi ini dapat diartikan bahwa diseminasi mengandung unsur penyebaran dan penghubung dari sesuatu yang bersifat ide, inovasi, atau penelitian agar dapat diketahui masyarakat.

Berdasarkan hal tersebut, maka penelitian ini akan menggali secara mendalam mengenai upaya komunikasi yang dilakukan oleh Public Relation Dinas Pariwisata dan Budaya di Provinsi NTB melalui diseminasi informasi terkait pariwisata berbasis lingkungan dan budaya guna meningkatkan daya tarik wisatawan.

\section{Metode Penelitian}

Pendekatan yang digunakan dalam penelitian ini adalah pendekatan kualitatif untuk mendeskripsikan dan menjelaskan bagaimana strategi public relations dalam melakukan diseminasi informasi terkait pariwisata berbasis lingkungan dan budaya guna meningkatkan daya tarik wisatawan dengan menguraikan ucapan, uraian, data, tulisan dan data-data deskriptif. Agar sesuai dengan permasalahan dan tujuan dari penelitian ini, maka yang menjadi subjek penelitian ditentukan berdasarkan karakteristik sebagai berikut: 1) Subjek terlibat dalam pelaksanaan strategi public relations dalam melakukan diseminasi informasi terkait pariwisata berbasis lingkungan dan budaya guna meningkatkan daya tarik wisatawan; 2) Subjek memiliki pengetahuan yang memadai mengenai strategi bagaimana strategi public relations dalam melakukan diseminasi informasi terkait pariwisata berbasis lingkungan dan budaya guna meningkatkan 
daya tarik wisatawan; 3) Memiliki kesediaan untuk diteliti dan menceritakan pengalamannya selama pelaksanaan strategi komunikasi tersebut.

Metode pengumpulan data yang digunakan dalam penelitian ini adalah wawancara mendalam (In-depth Interview) sebagai pengumpulan data primernya. Metode pengumpulan data sekunder dilakukan dengan studi pustaka melalui data yang didapatkan dari sumber literatur kepustakaan berupa buku-buku, surat kabar, artikel/tulisan pada media massa dan internet, foto, dokumen organisasi, website organisasi, serta hasil penelitian yang menjadi referensi dan yang berhubungan dengan strategi public relations.

\section{Hasil Penemuan dan Diskusi}

Hampir semua rencana pembangunan kepariwisataan NTB mengarah pada ecotourism dan budaya. Ini membuktikan bahwa keduanya menjadi andalan dari pariwisata di NTB. Hal ini dinyatakan pula oleh Kepala Promosi Dinas Kebudayaan dan Pariwisata NTB Utria Salim yang mengakui bahwa andalan utama pariwisata di NTB adalah berbasis alam dan budaya. Alam menjadi daya tarik dalam mempromosikan objek-objek wisata. Menurutnya, wisatawan lebih menyukai keindahan alam yang ada di Propinsi NTB seperti Pantai Senggigi, Pantai Kuta, dan Gili-Gili yang ada di sekitar Pulau Lombok.

Pariwisata juga menjadi sektor prioritas pembangunan di NTB setelah pertanian. Program ini menjadi perhatian utama karena memberi dampak ekonomi bagi provinsi. Wakil Gubernur NTB Muhammad Amin dikutip kompas.com menyatakan bahwa ada beberapa alasan pariwisata menunjukkan peningkatan sebagai potensi ekonomi unggulan, di antaranya daya tarik obyek wisata NTB yang sangat beragam, mulai dari wisata alam, wisata budaya, wisata kuliner danlainsebagainya.(http://travel.kompas.com/read/2015/12/11/182500627/Tren.Pa riwisata.NTB.Terus.Meningkat)

M. Amin mengatakan di tahun 2015 ini pemerintah pusat melalui Kementerian Pariwisata telah menetapkan NTB sebagai daerah pengembangan wisata syariah atau wisata halal selain Provinsi Sumatera Barat dan Aceh. "Ini tentu semakin membuka peluang pengembangan pariwisata NTB karena tampil dengan brand yang lebih kompetitif," ucapnya.

Dari pengamatan yang kami lakukan bahwa memang sektor ecotourism mendominasi destinasi wisata di NTB. Hal ini sesuai pernyataan yang disampaikan Gubernur NTB Muhammad Zainul Majdi dikutip Okezone.com bahwa secara konsep, ecotourism diyakini akan banyak menguntungkan NTB. Model pariwisatanya ramah lingkungan. Ada basis budaya setempat yang diangkat sebagai penguat objek destinasinya. Model pariwisata ini menjadi ideal karena berfungsi ganda. Selain itu, sebagai konservasi, observasi, serta sarana pendidikan. (http://news.okezone.com/read/2016/03/26/65/1346140/kampus-assiap-bantu-kembangkan-ecotourism-ntb). Pernyataan gubernur menjadi penanda arah kebijakan industri pariwisata NTB. Jumlah wisatawan yang datang ke NTB untuk tahun 2015 totalnya 2.210.527 wisatawan yang terdiri dari wisatawan mancanegara berjumlah 1.061.292 dan wisatawan nusantara 1.149.235 (http://www.disbudpar.ntbprov.go.id). Jumlah ini terus bertambah setiap 
Yugih Setyanto, Septia Winduwati : Diseminasi Informasi Terkait Pariwisata Berwawasan Lingkungan dan Budaya Guna Meningkatkan Daya Tarik Wisatawan (Studi pada Dinas Pariwisata Provinsi Nusa Tenggara Barat)

tahunnya. Pulau Lombok mendapatkan World's Best Halal Honeymoon Destination dan World's Best Halal Tourism Destination pada World Halal Travel Summit and Exhibition 2015 di Abu Dhabi, 19-21 Oktober 2015.

\section{Komunikasi dalam Aspek Diseminasi Informasi Pariwisata}

Komunikasi menjadi hal penting dalam diseminasi informasi yang dilakukan pemerintah. Dalam struktur pemerintahan, apa yang dilakjukan dinas pariwisata mengacu pada program yang besar yang telah digariskan pemerintah dalam membangun pariwisata.

Secara umum Dinas Pariwisata Nusa Tenggara Barat menjalankan fungsi komunikasi dalam kegiatan diseminasi informasi seperti disampaikan Roudhonah (2007) bahwa komunikasi memiliki fungsi mass information, mass education, mass persuasion dan mass entertainment yang memiliki teori yang sama dengan fungsi komunikasi menurut Effendy (1999) yaitu :

1. Menginformasikan (to inform)

Memberikan informasi kepada masyarakat, memberitahukan kepada masyarakat mengenai peristiwa yang terjadi, ide atau pikiran dan tingkah laku orang lain, serta segala sesuatu yang disampaikan orang lain. Dinas Pariwisata memberikan informasi kepada masyarakat mengenai apa saja yang dapat dilihat dan dikunjungi di NTB terkait pariwisata budaya dan lingkungan melalui melalui berbagai saluran dan kegiatan. Dinas Pariwisata Provinsi Nusa Tenggara Barat (NTB) mempromosikan Pulau Lombok ditujukan kepada para masyarakat yang memiliki kemungkinan untuk menjadi wisatawan yang akan mengunjungi Pulau Lombok agar mendapatkan informasi mengenai Kepulauan Lombok. Selain para calon wisatawan, informasi juga diberikan kepada para agen tour wisata untuk membantu Dinas Pariwisata Provinsi Nusa Tenggara Barat (NTB) dalam memberikan informasi kepada para wisatawan mengenai Pulau Lombok. Salah satu informasi yang diberikan oleh Dinas Pariwisata Provinsi Nusa Tenggara Barat (NTB) dengan meggunakan media website Pesona Indonesia dan Wonderful Indonesia. Pada website diberikan informasi mengenai suasana di Pulau Lombok, Nusa Tenggara Barat dengan seolah berada di planet yang lain karena menemukan hal yang luar biasa dan mencengangkan Ecotourism dengan keindahan pantainya yang menawan dan kekayaan budaya yang sangat beragam. Deskripsi suasana yang tercantum dalam website memberikan gambaran sekaligus untuk mempromosikan objek wisata yang ada.

"Dengan pantai-pantai yang indah nan ajaib, Gunung Agung Rinjani dan kehidupan laut spektakuler yang menarik untuk dijelajah, pulau lombok di Nusa Tenggara Barat memiliki banyak destinasi wisata baik di darat maupun di laut. Tidak heran jika Lombok adalah destinasi terpopuler di Nusa Tenggara Barat." 

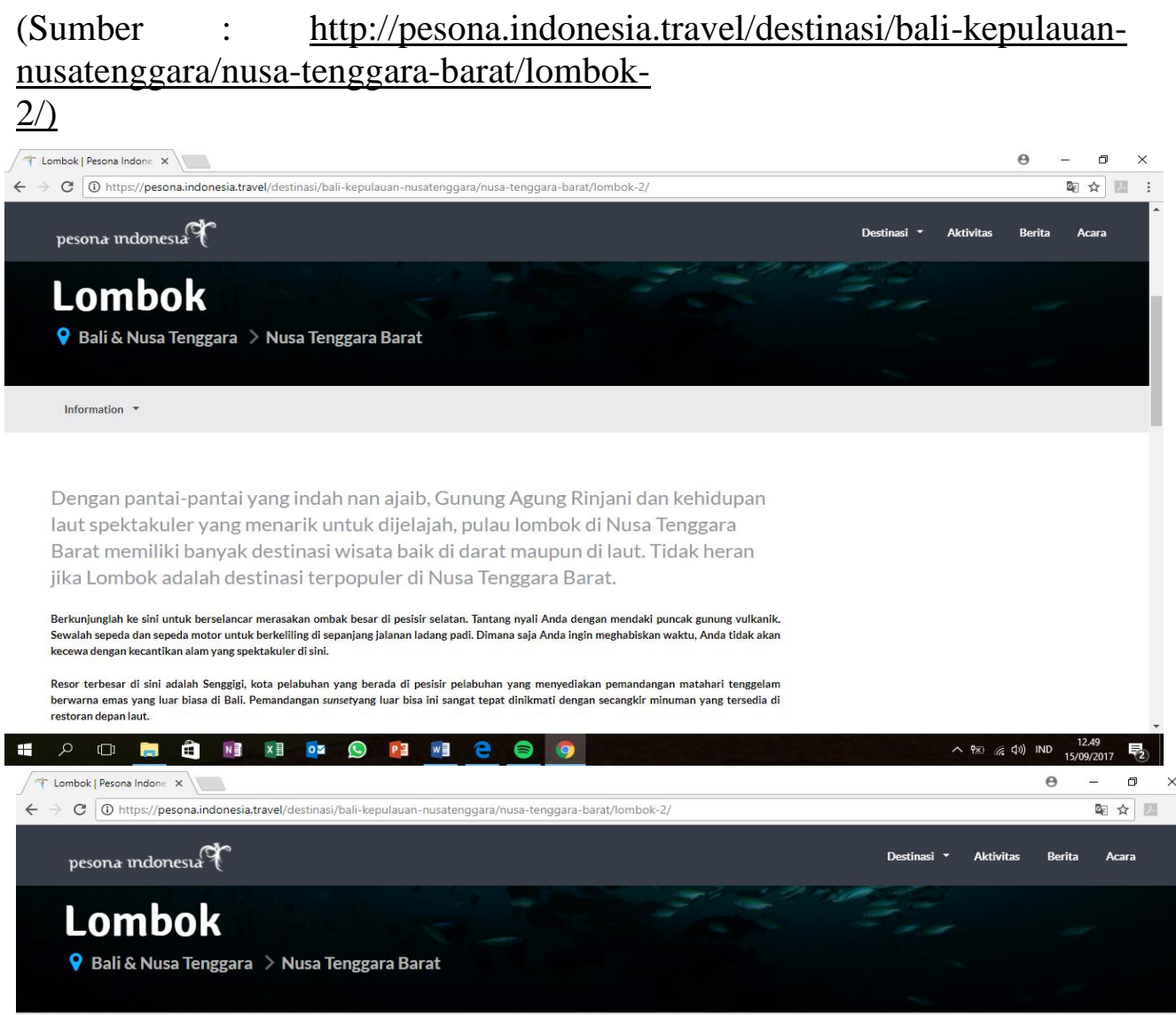

Intormation -

Dengan pantai-pantai yang indah nan ajaib, Gunung Agung Rinjani dan kehidupan laut spektakuler yang menarik untuk dijelajah, pulau lombok di Nusa Tenggara Barat memiliki banyak destinasi wisata baik di darat maupun di laut. Tidak heran jika Lombok adalah destinasi terpopuler di Nusa Tenggara Barat.

Berkunjunglah ke sini untuk berselancar merasakan ombak besar di pesisir selatan. Tantang nyali Anda dengan mendaki puncak gunung vulkanik. Sewalah sepeda dan sepeda motor untuk berkeliling di sepanjang jalanan ladang padi. Dimana saja Anda ingin meghabiskan waktu, Anda tidak akan kecewa dengan kocantikan alam yang spektakuler di sini.

Resor terbesar di sini adalah Senggigi, kota pelabuhan yang berada di pesisir pelabuhan yang menyediakan pemandangan matahari tenggelam

berwarna emas vang luar biasa di Ball. Pemandangan sunsetyang luar bisa ini sangat tepat dinikmati dengan secangkir minuman yang tersed 2 d
restorand depanlaut.

* 0 [ᄆ]

\section{Gambar 1: Website Pesona Indonesia Sebagai Sarana Diseminasi Informasi}

2. Mendidik (to educate),

Fungsi komunikasi sebagai sarana pendidikan. Dinas Pariwisata Provinsi Nusa Tenggara Barat (NTB) memberikan edukasi pengetahuan mengenai topografi pulau-pulau yang ada di kepulauan Lombok sehingga menambah pengetahuan dan menjadi pendidikan bagi masyarakat. Edukasi yang diberikan oleh Dinas Pariwisata Provinsi Nusa Tenggara Barat (NTB) ditujukan kepada para calon wisatawan agar para calon wisatawan dapat mengetahui tentang pulau-pulau dan daerah yang dapat dikunjungi mengenai keadaan, cuaca dan gambaran kondisi pulau Lombok. Salah satu 
Yugih Setyanto, Septia Winduwati : Diseminasi Informasi Terkait Pariwisata Berwawasan Lingkungan dan Budaya Guna Meningkatkan Daya Tarik Wisatawan (Studi pada Dinas Pariwisata Provinsi Nusa Tenggara Barat)

edukasi yang diberikan adalah pengetahuan mengenai tempat wisata yaitu resor terbesar di pulau Lombok adalah Senggigi, kota pelabuhan yang berada di pesisir pelabuhan yang menyediakan pemandangan matahari tenggelam berwarna emas yang luar biasa di Bali. Pemandangan sunset yang luar bisa ini sangat tepat dinikmati dengan secangkir minuman yang tersedia di restoran depan laut. Pengunjung lain di Lombok memilih untuk menghabiskan waktu mereka di pulau Gili-Gili, pulau tropis yang terpencil dengan pantai-pantai yang luar biasa indahnya dan lingkungan sekitar yang mewah. Penduduk asli Lombok adalah Sasak, Lombok juga rumah bagi umat Hindu Bali dan juga sejumlah orang Cina, Jawa, Bugis dan Arab. (http:// (Sumber: http://pesona.indonesia.travel/destinasi/balikepulauan-nusatenggara/nusa-tenggara-barat/lombok-2/).

3. Menghibur (to entertaint)

Fungsi komunikasi selain menyampaikan pendidikan, dan mempengaruhi, komunikasi juga berfungsi untuk memberi hiburan atau menghibur orang lain. Dinas Pariwisata Provinsi Nusa Tenggara Barat (NTB) memberikan hiburan kepada masyarakat dengan menampilkan video, gambar atau foto mengenai Pulau Lombok melalui media cetak, eletkronik dan sosial. Tampilan foto, video, dan gambar ditampilkan oleh Dinas Pariwisata Provinsi Nusa Tenggara Barat (NTB) melalui media massa dan media sosial sebagai media kegiatan promosi Pulau Lombok memberikan hiburan dan menjadi daya tarik bagi masyarakat Indonesia agar dapat menjadi wisatawan Kepulauan Lombok. Video dalam bentuk liputan feature pemandangan pulau-pulau Lombok dibuat oleh Kementerian Pariwisata dengan mencantumkan brand Pesona Indonesia dan Wonderful Indonesia ditampilkan melalui media elektronik televisi dan media sosial Youtube. (https://www.youtube.com/watch?v=BbkFE_K_t0c).

4. Mempengaruhi (to influence)

Fungsi memperngaruhi setiap individu yang berkomunikasi, tentunya berusaha saling mempengaruhi jalan pikiran komunikan dan lebih jauh lagi berusaha merubah sikap dan tingkah laku komunikan sesuai dengan apa yang diharapkan. Dinas Pariwisata Provinsi Nusa Tenggara Barat (NTB) melakukan komunikasi secara persuasif untuk mengajak para masyarakat agar memiliki keinginan untuk mengunjungi Dinas Pariwisata Provinsi Nusa Tenggara Barat (NTB) melalui pesan-pesan verbal dan nonverbal yang dapat menarik minat para masyarakat Indonesia. Kegiatan persuasi Dinas Pariwisata Provinsi Nusa Tenggara Barat (NTB) ditujukan agar masyarakat Indonesia dapat tertarik untuk berkunjung ke Kepulauan Lombok menjadi wisatawan Pulau Lombok yang terletak di provinsi Nusa Tenggara Barat dilakukan dengan menyusun kata-kata yang menarik yang ditampilkan pada website Pesona Indonesia. 
"Berkunjunglah ke sini untuk berselancar merasakan ombak besar di Pesisir Selatan. Tantang nyali Anda dengan mendaki puncak gunung vulkanik. Sewalah sepeda dan sepeda motor untuk berkeliling di sepanjang jalanan ladang padi. Dimana saja Anda ingin meghabiskan waktu, Anda tidak akan kecewa dengan kecantikan alam yang spektakuler disini." (Sumber:http://pesona.indonesia.travel/destinasi/bali-kepulauan nusatenggara/nusa-tenggara-barat/lombok-2/)

Teori Harold D Lasswel dalam buku Roudhonah (2007) menyebutkan bahwa tujuan komunikasi ada empat, yaitu adanya Social Change (Perubahan Sosial), Attitude Change (Perubahan Sikap), Opinion Change (Perubahan Pendapat), dan Behavior Change (Perubahan Perilaku). Hal ini sesuai dengan tujuan dari komunikasi yang dilakukan oleh Dinas Pariwisata Provinsi Nusa Tenggara Barat (NTB) dalam mempromosikan Kepulauan Lombok untuk perubahan sosial, sikap, pendapat, dan perilaku agar para masyarakat Indonesia untuk mau mengunjungi Kepulauan Lombok.

Tujuan dari diadakanya Promosi Kepulauan Lombok melalui Pesona Indonesia dan Wonderful Indonesia ini adalah untuk melakukan persuasif kepada target promosi yaitu para masyarakat lokal maupun mancanegara dapat menjadi wisatawan yang berkunjung ke Kepulauan Lombok. Menurut Effendy (2004), tujuan dari persuasi adalah untuk mengubah perilaku, sikap, maupun pendapat dari target persuasi serupa dengan yang dimaksud oleh Jalaluddin (1996) komunikasi persuasif menggambarkan bahwa kegiatan komunikasi persuasif berusaha menarik minat mitra komunikasi agar mempunyai perasaan satu kelompok (in group) yang diungkapkan dengan kesetiaan, solidaritas, kesenangan dan kerjasama. Dengan melakukan komunikasi di dalam promosi, Dinas Pariwisata Provinsi Nusa Tenggara Barat (NTB) berharap Promosi Kepulauan Lombok melalui Pesona Indonesia dan Wonderful Indonesia, dapat mengubah perilaku dan sikap dari masyarakat lokal dan mancanegara untuk mau dan memilih berkunjung ke Kepulauan Lombok dan mengubah pendapat para masyarakat bahwa wisata Indonesia tidak kalah menarik dari wisata negera lain.

\section{Strategi penyebaran Informasi Pariwisata}

Pengertian mengenai diseminasi disampaikan Welch-Ross dan Fasig (2007) dissemination of behavioral science refers to the spreading innovations from science to promote widespread awerness, understanding and use. Dari dua penjelasan mengenai diseminasi ini dapat diartikan bahwa diseminasi mengandung unsur penyebaran dan penghubung dari sesuatu yang bersifat ide, inovasi, atau penelitian agar dapat diketahui masyarakat.

Arah kebijakan pariwisata NTB yang mengedepankan ecotourism dan juga wisata budaya yang promosinya disebarkan melalui berbagai upaya komunikasi. Untuk mendukung upaya tersebut perlu diciptakan brand image akan keindahan alam di NTB. Upaya yang dilakukan untuk memperkenalkan ecotourism dan budaya adalah dengan kegiatan: 
Yugih Setyanto, Septia Winduwati : Diseminasi Informasi Terkait Pariwisata Berwawasan Lingkungan dan Budaya Guna Meningkatkan Daya Tarik Wisatawan (Studi pada Dinas Pariwisata Provinsi Nusa Tenggara Barat)

1. Publikasi media

Pemanfaatan media sebagai sarana publikasi dan promosi kegiatan serta destinasi wisata yang dapat menarik wisatawan. Sebagai contoh saat memperingati 200 tahun dahsyatnya Gunung Tambora meletus melalui event "Tambora Menyapa Dunia". Event ini bekerja sama dengan Harian Kompas untuk mempublikasikannya kepada masyarakat. Tentu kerja sama dengan media ini sebagai upaya yang dapat memperluas pengenalan masyarakat kepada NTB dimana Gunung Tambora berada serta eventevent yang diadakan oleh Dinas Pariwisata NTB.

Dalam kajian public relation kegiatan ini adalah bentuk media relations yang berujung pada publikasi positif. Media relations mempunyai manfaat dalam penyampaian/ perolehan informasi yang akurat, jujur, dan mampu memberikan pencerahan bagi publik (Nova, 2009).

Dalam hal ini apa yang dilakukan Disbudpar NTB adalah sebuah fungsi public relations dalam memanfaatkan hubungan yang baik dengan media untuk dapat mempublikasikan kegiatan "Tambora Menyapa Dunia" agar dikenal masyarakat. Namun tetap ada beberapa kendala dalam membangun hubungan baik dengan media.

Namun yang paling penting dari publikasi kegiatan ini adalah makin dikenalnya Gunung Tambora sebagai salah satu lokasi ecotourism yang bukan saja karena keindahan alamnya, namun juga peristiwa alam yang diakibatkan oleh aktivitas vulkanik gunung tersebut. Publikasi ini sekaligus dapat memperkuat citra Gunung Tambora sebagai salah satu destinasi wisata di NTB.

2. Menyelenggarakan kegiatan rutin

Guna mempromosikan destinasi wisata di NTB agar menarik wisatawan untuk datang adalah dengan menyelenggarakan kegiatan tahunan. Pemda NTB didukung pemerintah pusat dalam rangka program "Wonderful Indonesia" menyelenggarakan beberapa kegiatan pariwisata yang berbasis pada alam seperti "Tambora Menyapa Dunia" dalam rangka memperingati 200 tahun letusan dahsyat Gunung Tambora, Marathon "Rinjani Ultra 100 2016", perayaan Festival Bau Nyale di Pantai Kuta Lombok, Putri Mutiara NTB, dll. Semua kegiatan pariwisata ini diselenggarakan ini dapat memperkuat brand image NTB sebagai destinasi ecotourism.

Melaksanakan sebuah event dalam kaitannya dengan kegiatan public relations diulas oleh Firsan Nova (2009) mengutip Ruslan bahwa event merupakan bagian dari strategi public relations atau yang lebih dikenal dengan bauran public relations. Event disampaikannya sebagai upaya memperkenalkan produk dan layanan perusahaan, mendekatkan diri kepada publik, dan lebih jauh lagi dapat mempengaruhi opini publik.

Masih menurut Ruslan dikutip Firsan Nova bahwa jenis events adalah calender event yaitu yang bersifat rutin, special event contohnya seperti launching produk, peresmian pabrik, dll dan moment event yaitu 
acara yang bersifat momentum contohnya pesta emas. Dari penjelasan di atas dapat diartikan bahwa kegiatan (event) rutin yang diselenggarakan Pemda NTB adalah sebuah strategi public relation dengan tujuan memperkuat opini bahwa NTB sangat dekat dengan ecotourism.

\section{Direct Promotion}

Pemda NTB merasa perlu melakukan promosi pariwisata langsung ke sasaran. Sasaran yang dituju adalah calon wisatawan agar tertarik untuk berkunjung ke NTB. Untuk itu Pemda sudah memilih kota-kota besar di Indonesia yang menjadi sasaran dari promosi langsung. Kota tersebut adalah Jakarta, Surabaya, Makassar, Bandung, Batam dan Balikpapan. Di kota-kota tersebut dilakukan pertemuan dengan para pengusaha di industri pariwisata diantaranya agen perjalanan dll.

Menurut Levine (2003) public relations can create a brand, establish it, promote it, develop it, and keep it healthy, all without detected by general public. Salah satu yang dapat diciptakan oleh public relations adalah brand yang kemudian brand tersebut dipromosikan. Tentu jika mengacu pada pendapat Levine upaya direct promotion adalah usaha menciptakan brand pariwisata di Lombok yang berbasis pada alam.

Kegiatan yang dilakukan di atas dapat dijadikan sebuah upaya diseminasi yang dilakukan pemerintah NTB dalam mempromosikan sektor lingkungan dan budaya dalam menaikkan jumlah wisatawan. Namun selain upaya menaikkan jumlah wisatawan, hal penting yang juga harus diperhatikan dalam proses diseminasi informasi adalah khalayak sasaran. Sasaran diseminasi sebaiknya juga ditujukan pada masyarakat NTB pada umumnya dan masyarakat sekita objek wisata khususnya.

Proses komunikasi yang dilakukan harus dapat juga menumbuhkan pemahaman akan pentingnya potensi pariwisata dari sisi ekonomi. Oleh sebab itu masyarakat harus dilibatkan dalam pengelolaan objek wisata. Bukan semata ikut terlibat namun juga menjaga dengan baik potensi yang ada. Dengan kata lain, melalui diseminasi informasi juga dapat memberdayakan masyarakat untuk menunjang program pariwisata serta menaikkan pendapatan masyarakat.

\section{Simpulan}

Menjadikan lingkungan dan budaya sebagai nilai jual adalah bentuk diferensiasi yang dilakukan pemerintah NTB agar lebih dikenal oleh masyarakat. Kedua jenis objek tersebut tentu sudah melalui proses kajian mengenai potensi kekuatan pariwisata yang ada di NTB. Agar potensi pariwisata yang ada dapat dikenal lebih jauh dilakukan upaya diseminasi informasi mengenai potensi tersebut. Tujuan diseminasi juga sebaiknya ditujukan untuk pemberdayaan masyarakat. Masyarakat di sekitar objek harus terlibat dalam upaya pengembangan potensi wisata yang ada. 
Yugih Setyanto, Septia Winduwati : Diseminasi Informasi Terkait Pariwisata Berwawasan Lingkungan dan Budaya Guna Meningkatkan Daya Tarik Wisatawan (Studi pada Dinas Pariwisata Provinsi Nusa Tenggara Barat)

Oleh sebab itu proses diseminasi informasi mengenai pariwisata dan bukan sekedar pada bagaimana menarik wisatawan untuk datang. Hal yang tak kalah penting adalah bagaimana mengkomunikasikan manfaat objek wisata bagi masyarakat. Untuk itu, diseminasi informasi harus dilakukan untuk menumbuhkan pemahaman bahwa objek wisata yang ada memiliki nilai ekonomis bagi masyarakat. Tujuan akhirnya adalah masyarakat dengan inisiatifnya sendiri akan mengelola objek sebaiknya mungkin sehingga berdampak pada bergeraknya roda ekonomi melalui industri pariwisata.

\section{Ucapan Terima Kasih}

Penulis mengucapkan terima kasih dan penghargaan yang sebesarbesarnya atas dukungan semua pihak yang berkontribusi pada penelitian ini.

\section{Daftar Pustaka}

Effendy, Onong Uchyana. (1999). Ilmu Komunikasi, Teori dan Praktek. Bandung: Remaja Rosdakarya.

Effendy, Onong Uchyana. (2004). Dinamika Komunikasi. Bandung: Remaja Rosdakarya.

Indonesia Travel. (2013, November 16). Wonderful Indonesia - Lombok. Retrieved Januari 19, 2015, from Youtube: https://www.youtube.com/watch?v=BbkFE_K_t0cl

Kampus AS Siap Bantu Kembangkan Ecotourism NTB. (2016, Maret 26). Retrieved Juni 23, 2016, from Okezeno Online: http://news.okezone.com/read/2016/03/26/65/1346140/kampus-as-siapbantu-kembangkan-ecotourism-ntb

Levine, Michael. (2003). A Branded World: Adventures in Public Relations and the Creation of Superbrands. USA: John Wiley \& Sons, Inc.

Lombok. Retrieved Januari 19, 2015, from website pesona Indonesia: http://pesona.indonesia.travel/destinasi/bali-kepulauan-nusatenggara/nusatenggara-barat/lombok-2/

Nova, Firsan. (2009). Crisis Public Relation: Bagaimana PR Menangani Krisis Perusahaan. Jakarta: Grasindo.

Peraturan Mentri Pariwisata dan Ekonomi Kreatif Republiik Indonesia. Diakses pada 19 Januari 2015. data terarsip di: http://parekraf.go.id/userfiles/file/PERMEN\%20PAREKRAF\%20FINAL $\% 2013 \% 2002 \% 202012 . p d f$

Rakhmat, Jalaluddin. (1996). Psikologi Komunikasi, cetakan 10. Bandung: Rosdakarya.

Roudhonah. (2007). Ilmu Komunikasi. Jakarta: UIN Jakarta Press.

Tren Pariwisata NTB Terus Meningkat. (2015, November 12). Retrieved Desember 20, 2015, form Kompas Online: http://travel.kompas.com/read/2015/12/11/182500627/Tren.Pariwisata.NT B.Terus.Meningkat 
Tulung, H. Freddy. (2014). Berkomunikasi di Ruang Publik: Implementasi Kehumasan Pemerintah. Indonesia: Direktorat Jenderal Informasi dan Komunikasi Publik Kementrian Komunikasi dan Informatika RI.

Welch-Ross, Mellisa K., \& Fasig, Lauren G. (2007). Handbook on Communicating and Disseminationg Behavioral Science. USA: Sage Publication, Inc. 